\title{
Design of a Simple, Effective and Low Cost Micro-Wind Energy Conversion System
}

\author{
Massimiliano Luna, Marcello Pucci and Gianpaolo Vitale*
}

I.S.S.I.A.-C.N.R. Sezione di Palermo, Institute on Intelligent Systems for the Automation - National Council of Research. Section of Palermo, Italy

\begin{abstract}
This paper proposes a micro-wind energy conversion system, which is conceived for low speed operation and low power applications connected to the distribution network. Therefore it is devised on the basis of a trade-off between cost reduction and simplicity from one side, and good performance on the other side. Hardware components and their control are described thoroughly. The performance of the system is verified by numerical simulations with Simulink and PLECS and the obtained results are presented to support the proposed system.
\end{abstract}

Keywords: Micro Wind Energy Conversion System, boost converter, PMSM, MPPT, VOC.

\section{INTRODUCTION}

Wind energy exploitation has been significantly increasing during the last 10 years. Both wind power plants located in large wind parks and small-scale systems integrated into built environment are concerned. As a consequence, the market for urban applications has grown rapidly year after year. Microgeneration deals with generation technologies with rated power output below $50 \mathrm{~kW}$ or, for domestic installation, below $3 \mathrm{~kW}$. Taking into account the new workframe in the deregulated electric markets, it is expected that the installation of micro-wind turbine generators, also known as micro-wind energy conversion systems ( $\mu \mathrm{WECS}$ ), connected to low-voltage local networks will undergo a considerable increase, taking power generation plants closer to consumption centers and contributing to the stability of those networks [1-5].

The feasibility of this kind of installation depends on the system performance and cost. Customers' requirements are robustness, light control algorithms to use simple and cheap microprocessors and a simplified power conversion system to increase reliability. On the other hand $\mu$ WECS are generally located in urban areas, where wind is normally weak, turbulent and unstable in terms of direction and speed than those open sites preferable for wind farms, because of the existence of buildings and other adjacent obstructions [2]

Therefore energy harvesting implies the plant exploitation with systems optimized for low wind speed, yet capable of variable speed operation with fast settling time by means of suitable devised Maximun Power Point Tracking (MPPT) algorithms.

For such applications, the permanent-magnet synchronous machine (PMSM) is increasingly used. A PMSM is a

*Address correspondence to this author at the I.S.S.I.A.-C.N.R. Sezione di Palermo. Via Dante n. 12. 90141 Palermo, Italy; Tel: +390916113513; Fax:+390916113028; E-mail: gianpaolo.vitale@ieee.org rotating electric machine in which the field excitation is given by permanent magnets. The advantages of PM machines include: brushless construction, high torque versus volume ratio, high power versus volume ratio, light weight, small size, high reliability, less frequent maintenance, and high efficiency [6].

The main disadvantage, however, is that the excitation cannot be varied and hence the output voltage of the generator will vary with load. From practical considerations, it is desirable to minimize the voltage variation at the output of the generator. This may be accomplished by capacitor compensation, by electronic voltage controllers, or by using a generator with inherent voltage regulation capability [7].

This paper proposes a $\mu$ WECS which is conceived for low power applications connected to the distribution network. It has been devised on the basis of a trade-off between cost reduction and simplicity from one side and good performance on the other side. It encompasses an uncontrolled three-phase PMSM, a simple energy conversion system and a single-phase grid inverter.

The paper is organized as follows. Section II is dedicated to the description of the main components of the system: the PMSM machine, the micro-wind turbine, the energy conversion system and the control scheme. The performance of the system is illustrated in section III, where two characterizing scenarios are analysed, dealing with a small time scale and a daily scale respectively. Finally, some conclusions are given in section IV.

\section{SYSTEM ARCHITECTURE}

All the hardware components of the proposed system and their control scheme are described thoroughly in the following.

\section{A. PMSM Machine}

The adopted wind generation system is based on a PMSM. In particular, an IMSM (Interior Magnet Synchro- 
nous Motor) has been used, whose dynamic model based on the space vector equations in the rotor reference frame can be written as:

$\left\{\begin{array}{c}\mathrm{u}_{\mathrm{sd}}=\mathrm{R}_{\mathrm{s}} \mathrm{i}_{\mathrm{sd}}+\mathrm{L}_{\mathrm{sd}} \mathrm{di}_{\mathrm{sd}} / \mathrm{dt}-\mathrm{L}_{\mathrm{sq}} \omega_{\mathrm{r}} \mathrm{i}_{\mathrm{sq}} \\ \mathrm{u}_{\mathrm{sq}}=\mathrm{R}_{\mathrm{s}} \mathrm{i}_{\mathrm{sq}}+\mathrm{L}_{\mathrm{sq}} \mathrm{di}_{\mathrm{sq}} / \mathrm{dt}+\mathrm{L}_{\mathrm{sd}} \omega_{\mathrm{r}} \mathrm{i}_{\mathrm{sd}}+\omega_{\mathrm{r}} \psi_{\mathrm{F}}\end{array}\right.$

where $\mathrm{u}_{\mathrm{sd}}, \mathrm{u}_{\mathrm{sq}}$ are the direct and quadrature components of the stator voltage, $i_{\mathrm{sd}}, \mathrm{i}_{\mathrm{sq}}$ the direct and quadrature components of the stator current, $\mathrm{L}_{\mathrm{sd}}, \mathrm{L}_{\mathrm{sq}}$ are the direct and quadrature stator inductances, $\psi_{\mathrm{F}}$ is the excitation flux linkage, $R_{\mathrm{s}}$ is the resistance of the stator windings and $\omega_{\mathrm{r}}$ is the rotor speed (in electrical angles). The corresponding electromagnetic torque equation is:

$\mathrm{t}_{\mathrm{e}}=\frac{3 \mathrm{p}}{2}\left(\mathrm{i}_{\mathrm{q}} \psi_{\mathrm{F}}+\left(\mathrm{L}_{\mathrm{sd}}-\mathrm{L}_{\mathrm{sq}}\right) \cdot \mathrm{i}_{\mathrm{sd}} \mathrm{i}_{\mathrm{sq}}\right)$

where $p$ is the number of pole pairs. The electromagnetic torque is thus composed of one term due to the magnetization flux and a saliency torque term, due to the difference between the two axis inductances terms. Equations (1) and (2) with the well known mechanical equation of the system represent the complete model of the IMSM which has been used for the numerical tests.

\section{B. Micro-wind Turbine}

As in most modern systems, a standard horizontal axis, three-bladed micro-wind turbine has been used, with the rotor position maintained upwind. This design tends to be a standard against which other concepts are evaluated [8]. The basic advantage of upwind designs is that they allow to avoid the wind shade behind the tower. As to the number of rotor blades, it has an influence on the torque ripple and on the stability of the turbine. A rotor with an odd number of rotor blades (at least three blades) can be considered to be similar to a disc when evaluating the dynamic properties of the machine. On the contrary, a rotor with an even number of blades will give stability problems because when the uppermost blade gets the maximum power from the wind and bends backwards, the lowermost blade passes into the wind shade in front of the tower. Furthermore two-bladed wind turbines, despite the advantage of saving the cost of one rotor blade and its weight, require higher rotational speed to yield the same energy output. This is a disadvantage also in regard to noise and visual intrusion.

The wind turbine considered in the proposed system has been modelled as follows. The power generated by a wind turbine can be written as [9]:
$\mathrm{P}_{\mathrm{m}}=\mathrm{C}_{\mathrm{p}}(\lambda, \beta) \frac{\rho \mathrm{A}}{2} \mathrm{v}^{3}$

where $P_{m}$ is the mechanical power of the turbine in $[\mathrm{W}], \mathrm{C}_{\mathrm{p}}$ is the performance coefficient of the turbine, $\rho$ is the air density in $\left[\mathrm{kg} / \mathrm{m}^{3}\right], \mathrm{A}$ is the turbine swept area in $\left[\mathrm{m}^{2}\right], \mathrm{v}$ is the free wind speed in $[\mathrm{m} / \mathrm{s}], \lambda$ is the tip speed ratio defined as the ratio between the rotor blade tip and the free speed of the wind:

$\lambda=\frac{\omega_{\mathrm{T}} \mathrm{R}}{\mathrm{V}}$

where $\omega_{T}$ is the turbine angular speed and $R$ is the turbine radius. $\beta$ is the blade pitch angle in [deg], [10]:

$\mathrm{C}_{\mathrm{p}}(\lambda, \beta)=\mathrm{c}_{1}\left(\frac{\mathrm{c}_{2}}{\lambda_{\mathrm{i}}}-\mathrm{c}_{3} \beta-\mathrm{c}_{4}\right) \cdot \mathrm{e}^{-\frac{\mathrm{c}_{5}}{\lambda_{\mathrm{i}}}}+\mathrm{c}_{6} \lambda$

with

$\frac{1}{\lambda_{i}}=\frac{1}{\lambda+0.08 \beta}-\frac{0.035}{\beta^{3}+1}$

and $c_{1}=0.5176, c_{2}=116, c_{3}=0.4, c_{4}=5, c_{5}=21, c_{6}=0.0068$.

The torque produced by the turbine can be computed as:

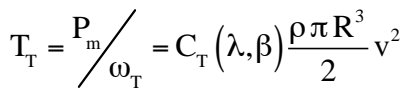

where the torque coefficient of the turbine is defined as $\mathrm{C}_{\mathrm{T}}(\lambda, \beta)=\mathrm{C}_{\mathrm{P}}(\lambda, \beta) / \lambda$.

It should be borne in mind that both turbine speed and torque should be converted into the machine speed range on the basis of the gear ratio $n$, as $\omega_{\mathrm{T}}{ }^{\prime}=\omega_{\mathrm{T}} \mathrm{n}=\omega_{\mathrm{rm}}$ and $\mathrm{T}_{\mathrm{T}}{ }^{\prime}=\mathrm{T}_{\mathrm{T}} / \mathrm{n}$.

The system should be optimized for low speed operation, since a one-year campaign of environmental data monitoring in a typical urban site showed the following parameters for wind speed:

- instantaneous values: $\min 0 \mathrm{~m} / \mathrm{s}, \max 11.2 \mathrm{~m} / \mathrm{s}$;

- values averaged over 6 minutes: $\min 1.4 \mathrm{~m} / \mathrm{s}$, average $3.8 \mathrm{~m} / \mathrm{s}$, $\max 8.2 \mathrm{~m} / \mathrm{s}$.

The analysis of the distribution of wind speed over one year has given the results shown in Table I. It allowed the reference values to be chosen for each speed range and to

Table I. Wind Speed Distribution

\begin{tabular}{|c|c|c|c|c|}
\hline & Night hours & $\begin{array}{c}\text { Day hours with low } \\
\text { wind speed }\end{array}$ & $\begin{array}{c}\text { Day hours with medium wind } \\
\text { speed }\end{array}$ & $\begin{array}{c}\text { Day hours with high wind } \\
\text { speed }\end{array}$ \\
\hline \hline \begin{tabular}{c} 
Speed range $[\mathrm{m} / \mathrm{s}]$ \\
\hline $\begin{array}{c}\text { Reference value for each speed range } \\
{[\mathrm{m} / \mathrm{s}]}\end{array}$
\end{tabular} & $0 \div 4$ & $4 \div 6.5$ & $>6.5$ \\
\hline Frequency & 2.5 & 5 & 9 \\
\hline
\end{tabular}


match the PMSM with the wind turbine, by imposing that the maximum torque of the machine equals the torque exhibited by the wind turbine in the maximum power point (MPP) when the wind speed is $\mathrm{v}=6.5 \mathrm{~m} / \mathrm{s}$. The main parameters of the chosen PMSM machine are shown in Table II, while the adopted turbine model parameters are shown in Table III.

The operation of the MPPT involves a matching between the characteristic curves of the PMSM machine and the wind turbine. For a given wind speed the turbine characteristic is uniquely determined. On the other hand the machine characteristic can be suitably varied by changing the load which is seen by the output terminals of the machine.

\section{Table II. PMSM Parameters}

\begin{tabular}{|l|c|}
\hline direct-axis inductance $[\mathrm{H}]$ & $8.26 \cdot 10^{-3}$ \\
\hline quadrature-axis inductance $[\mathrm{H}]$ & $13.64 \cdot 10^{-3}$ \\
\hline permanent magnets flux $[\mathrm{Wb}]$ & $8.443 \cdot 10^{-2}$ \\
\hline stator windings resistance $[\Omega]$ & 2.21 \\
\hline number of pole-pairs & 3 \\
\hline inertia momentum $\left[\mathrm{kg} \cdot \mathrm{m}^{2}\right]$ & $2 \cdot 10^{-4}$ \\
\hline viscosity resistance $[\mathrm{N} \cdot \mathrm{m} \cdot \mathrm{s} / \mathrm{rad}]$ & $1 \cdot 10^{-4}$ \\
\hline
\end{tabular}

Table III. Wind Turbine Parameters

\begin{tabular}{|c|c|}
\hline $\mathrm{R}[\mathrm{m}]$ & 2 \\
\hline$\lambda_{\text {opt }}$ & 8.1 \\
\hline $\mathrm{C}_{\mathrm{pmax}}$ & 0.48 \\
\hline $\mathrm{n}$ & 6.2 \\
\hline $\begin{array}{c}\text { Peak power [W] } \\
\text { (at } 8 \mathrm{~m} / \mathrm{s} \text { wind speed) }\end{array}$ & 1500 \\
\hline Peak speed [rpm] & 2500 \\
\hline $\begin{array}{c}\text { Rated power [W] } \\
\text { (at 6.5 m/s wind speed) }\end{array}$ & 900 \\
\hline Rated speed [rpm] & 1600 \\
\hline
\end{tabular}

To this aim a power converter can be used because it absorbs a current which depends on a control signal, behaving as an apparent variable resistance connected to the PMSM machine. As the control of the energy conversion system varies this resistance, the characteristic of the PMSM can be expanded or reduced on the horizontal axis. This allows to vary the intersection with the characteristic of the wind turbine, so that stable operating points can be found also at very low wind speeds. Then the operation of a MPPT circuit will try to select the value of the apparent load resistance which corresponds to the operation in the MPP at a given wind speed.

Fig. (1) shows the torque versus speed characteristics of the wind turbine (black), obtained for two values of the free wind speed, as well as the characteristics of the PMSM

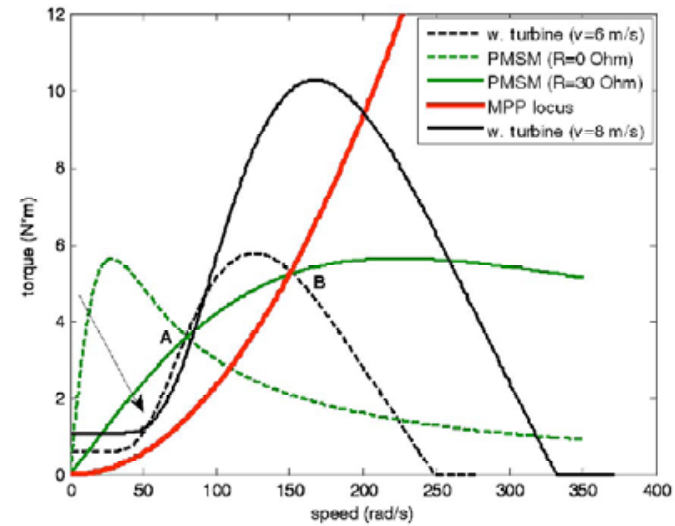

Fig. (1). Torque $v s$ speed characteristics for wind turbine and PMSM; MPP locus vs rotating speed.

(green) for two values of the apparent load resistance; it shows also the locus of the maximum power points (red) for each rotating speed. In particular Fig. (1) shows that, supposing that the wind speed is $6 \mathrm{~m} / \mathrm{s}$ and the initial value of the apparent resistance is $0 \Omega$ (point A), the MPPT increases the apparent resistance to the value $(30 \Omega)$ corresponding to the MPP (point B).

The size of the PMSM has been chosen on the basis of a trade-off. A small generator requires a low torque value to turn; therefore it will produce electricity during many hours of the year, even though it is not very efficient during the periods of high wind speed. A large generator, on the other hand, will be very efficient at high wind speeds, but unable to turn at low wind speeds.

The generator and rotor size affect the capacity factor of the wind turbine, defined as its actual annual energy output divided by the theoretical maximum output, if the machine were running at full per hour capacity $\mathrm{P}_{\mathrm{C}}$ during all of the 8766 hours of the year, according to the following equation:

$\mathrm{CF}=\frac{\mathrm{E}_{\text {year }}}{\mathrm{P}_{\mathrm{C}} \cdot 365.25 \cdot 24} \cdot 100$

Capacity factor may theoretically vary from $0 \%$ to $100 \%$, but usual values for wind turbines are around $25 \div 30 \%$.

\section{Energy Conversion System}

As shown in Fig. (2), the PMSM machine is connected to a three-phase uncontrolled rectifier whose output is the input of a DC/DC boost converter. A decoupling capacitor $(\mathrm{Cr}=650 \mu \mathrm{F})$ has been placed between the afore mentioned devices in order to reduce the ripple of the rectified voltage.

The boost converter is connected to a single-phase inverter and its design has been carried out imposing that it exhibited continuous-current conduction operation and an output voltage ripple lower than a few percent [11].

The following values have been obtained for the inductance and capacitance: $\mathrm{L}_{\mathrm{b}}=2 \mathrm{mH}$ and $\mathrm{C}_{\mathrm{b}}=23.5 \mu \mathrm{F}$. The boost capacitance is parallel connected to the input capacitance of the inverter $\left(C_{i n v}=1650 \mu \mathrm{F}\right)$, thus the actual voltage ripple is even lower. Each power switch in Fig. (2) is a MESH IGBT. The four devices of the inverter are driven by the modulator of the VOC controller described in section II.D, while the 


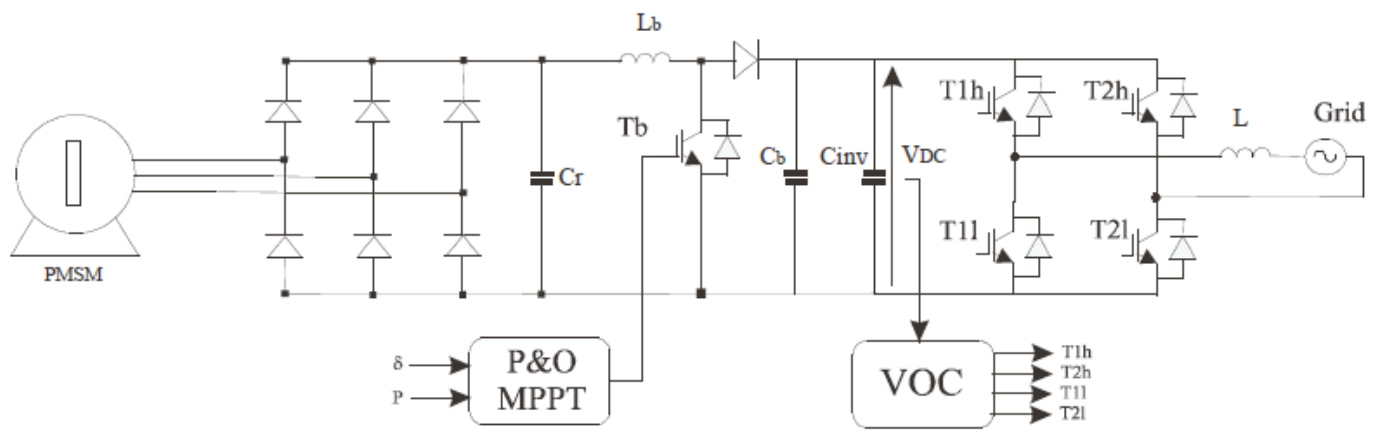

Fig. (2). Energy conversion system.

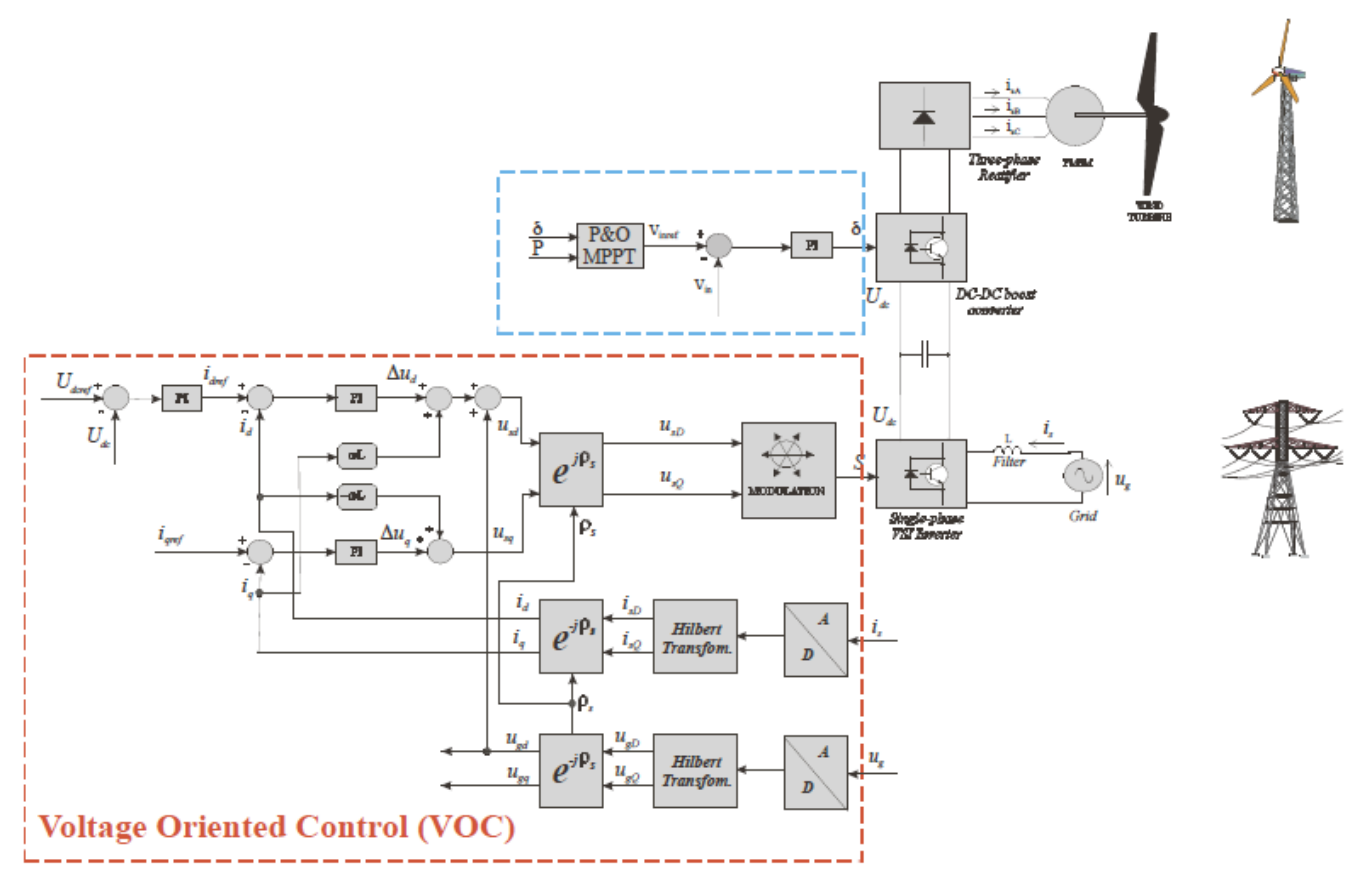

Fig. (3). Control scheme.

boost IGBT is driven by a conventional PWM signal, whose carrier has a frequency of $10 \mathrm{kHz}$, i.e. it is equal to the sampling frequency of the whole control system. This structure allows operation at variable speed for the generator, decoupling the network frequency from the shaft rotation speed.

\section{Control Scheme}

The complete control scheme of the system is sketched in Fig. (3). It can be observed that the adopted three-phase IMPM generator is not controlled at all, since its output voltage is rectified by a non-controlled diode bridge.

The control of the boost converter is performed by a conventional PI regulator, designed with traditional methods [12] aimed to get suitable steady state error, bandwidth and stability margins. The chosen control variable is the input voltage of the converter, which is at the same time the output voltage of the three-phase rectifier. By controlling this quantity it is possible to vary the speed of the PMSM and to track the MPP of the source, provided that the grid-connected single-phase inverter controls the DC link voltage to be constant.

Therefore, the reference voltage of the boost controller is set by a Maximum Power Point Tracking (MPPT) algorithm which, for the sake of simplicity, is based on the "perturb and observe" (P\&O) technique. It evaluates continuously the generated power which flows at the output of the boost converter, trying to maximize it by adjusting the duty cycle of the signal which drives the IGBT. Since the input signals of the MPPT circuit exhibit a ripple with a frequency value around $1500 \mathrm{~Hz}$, filters are needed for its proper operation. They have been designed in order to calculate the average values by taking 500 points in a $5 \mathrm{~ms}$ time window.

Grid side control has been performed on the basis of a high performance technique: Voltage Oriented Control (VOC) [13-15] which, conceived for a three-phase system, has been rearranged here for a single-phase system. VOC is based on the idea of decoupling instantaneously the direct (d) and quadrature (q) components of the injected current, working in the grid voltage vector reference frame.

In this synchronous reference frame, the voltage spacevector equation of the system, expressed in vector form, is:

$\mathbf{u}_{\mathrm{g}}^{\mathrm{u}}=\mathbf{u}_{\mathrm{sg}}^{\mathrm{u}}+\mathrm{L} \frac{\mathrm{d} \mathbf{i}_{\mathrm{sg}}^{\mathrm{u}}}{\mathrm{dt}}+\mathrm{R} \mathbf{i}_{\mathrm{sg}}^{\mathrm{u}}+\mathrm{j} \omega \mathrm{L} \mathbf{i}_{\mathrm{sg}}^{\mathrm{u}}$

The decomposition of such equation on the direct (d) and quadrature $(\mathrm{q})$ axis gives: 


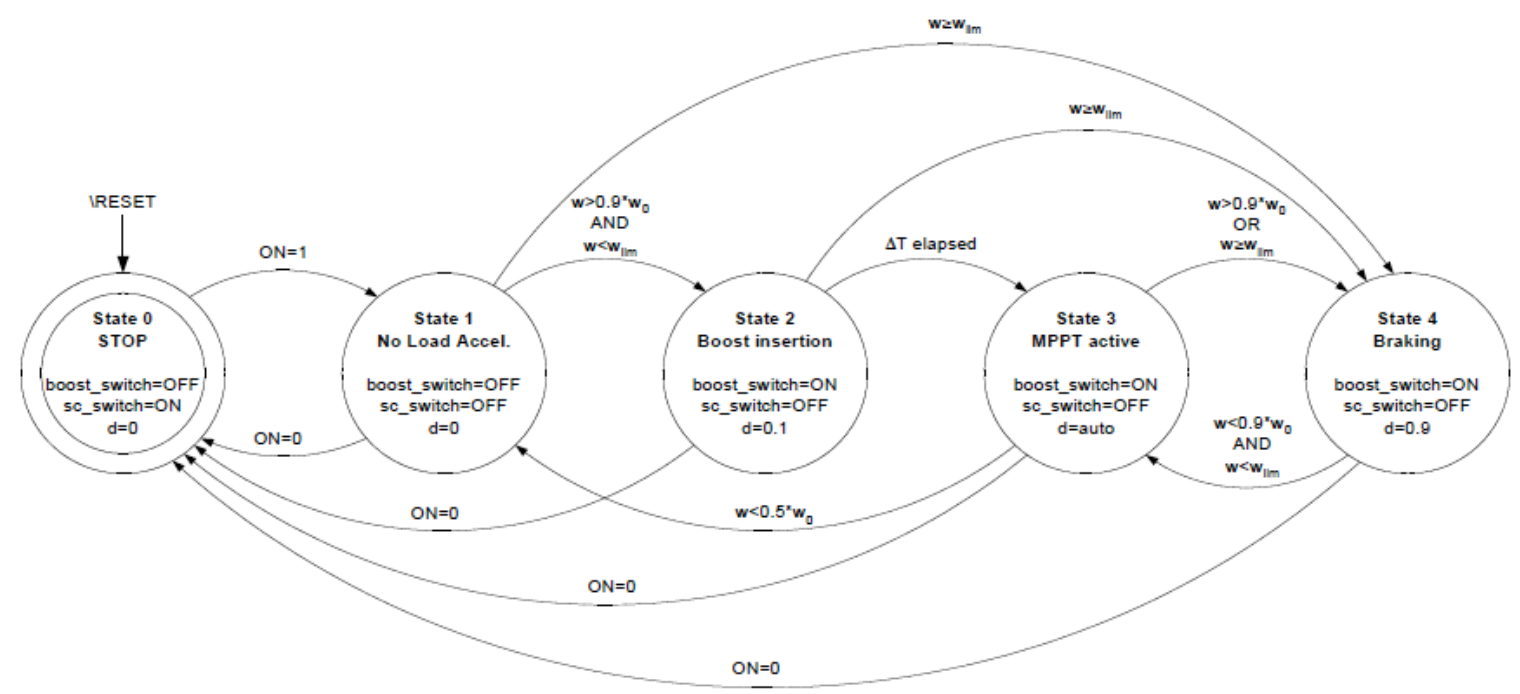

Fig. (4). State diagram of the FSM.

$$
\left\{\begin{array}{l}
\mathrm{u}_{\mathrm{gd}}=\mathrm{u}_{\mathrm{sgd}}+\mathrm{Ri}_{\mathrm{sgd}}+\mathrm{Ldi}_{\mathrm{sgd}} / \mathrm{dt}-\omega \mathrm{Li}_{\mathrm{sgq}} \\
\mathrm{u}_{\mathrm{gq}}=\mathrm{u}_{\mathrm{sgq}}+\mathrm{Ri}_{\mathrm{sgq}}+\mathrm{Ldi}_{\mathrm{sgq}} / \mathrm{dt}+\omega \mathrm{Li}_{\mathrm{sgd}}
\end{array}\right.
$$

Equations (10) show that the direct (quadrature) component of the injected currents depends on the direct (quadrature) component of the inverter voltages. Conventional PI controllers can then be used to control the inverter current components in the grid voltage oriented reference frame as in Fig. (3). However, as it happens in the electrical drive counterpart, there are some coupling terms on both axis equations, which should be compensated for with feed-forward control terms.

Since the target here is to control directly the DC link voltage, the control scheme has also a DC link voltage loop, external to the direct component current loop, whose output is the direct reference current. The quadrature current reference is always set to zero, so to maintain null the reactive power exchanged by the wind generation system with the grid.

The sampling frequency of the whole control system has been set to $10 \mathrm{kHz}$. It should be noted that the main difference with the three-phase counterpart is the presence of the Hilbert transformation blocks, which allow to generate the fictitious quadrature components of both the grid voltage and the injected current. This is essential to perform the voltage orientation needed for the connection of the system into the grid. With regard to the PWM technique of the grid connected single-phase inverter, a bipolar control of the VSI is performed; therefore the duty cycle $d$ of a leg can be computed on the basis of the DC link voltage $U_{d c}$ and the reference voltage $v_{\text {ref }}$ as:

$\mathrm{d}=\frac{\mathrm{v}_{\text {ref }}}{2 \mathrm{U}_{\mathrm{dc}}}+\frac{1}{2}$

Finally, a finite state machine (FSM) has been set up to drive the whole system through a set of pre-defined states, in order to manage the following conditions besides the normal operation:

1. the machine should not move when the whole system is turned off;
2. the machine speed should not increase above a safe maximum value $w_{\text {lim }}$ during wind gusts;

3. if more than one intersection exist between the characteristic of the wind turbine and the PMSM characteristic, then the machine should operate in the point which corresponds to the highest speed and thus to the highest generated power;

4. the settling time of the whole control system should be acceptable in every operating condition.

This task has been accomplished by using a set of switches, not shown in Figs. $(\mathbf{2}, \mathbf{3})$ for the sake of simplicity, which have been referred to as boost_switch and sc_switch. They can either connect the machine to the energy conversion system, or leave it floating in a no load condition, or connect it to low value resistors (short-circuit condition), according to Table IV. The state diagram of the FSM is shown in Fig. (4), where $d$ is the duty cycle of the signal which drives the IGBT of the boost converter.

Table IV. Effect of Switches on System Configuration

\begin{tabular}{|c|c|l|}
\hline boost_switch & sc_switch & \multicolumn{1}{c|}{ PMSM status } \\
\hline \hline OFF & OFF & floating (no load condition) \\
\hline OFF & ON & short-circuit condition \\
\hline ON & OFF & $\begin{array}{l}\text { connected to the energy conversion sys- } \\
\text { tem (boost operation) }\end{array}$ \\
\hline ON & ON & config. not allowed \\
\hline
\end{tabular}

The problem described in point 3 of the previous list is experienced especially at startup. It is solved firstly by starting up the PMSM in the no load condition (state 1, no load acceleration) and by connecting it to the energy conversion system only when its speed has reached $90 \%$ of the turbine's no load speed $w_{0}$ (state 2 , boost insertion). The relationship between the wind speed and $w_{0}$ is linear, so $w_{0}$ can be evaluated in real time. Then, after a short delay, the MPPT circuit will reduce the PMSM speed and will approach the MPP, 
while keeping the operating point on the right of the maximum of each torque vs. speed characteristic of Fig. (1) (state 3, MPPT active).

As to the dynamic behaviour, a sudden increase of the wind speed could let the machine speed fall below the value which corresponds to the maximum of the turbine's torque vs. speed characteristic, which is exactly $0.5 \cdot w_{0}$. If this is not the case, the MPPT circuit will approach the new MPP; otherwise the startup process is repeated (state $3 \rightarrow$ state 1 transition).

In order to accomplish point 4 of the previous list, if the wind speed decreases and lets the PMSM speed go above the no load speed $w_{0}$, the duty cycle of the boost converter is set to its maximum allowed value (state 4 , braking). This allows a fast reduction of the PMSM speed. When it becomes lower than $90 \%$ of the no load speed $w_{0}$, the MPPT circuit is activated again.

As to points 1 and 2 of the previous list, the comprehension of the FSM in Fig. (4) is straightforward.

\section{SIMULATION RESULTS}

The performance of the proposed system has been verified by different simulations with Simulink and PLECS, taking into account mechanical and electrical losses.
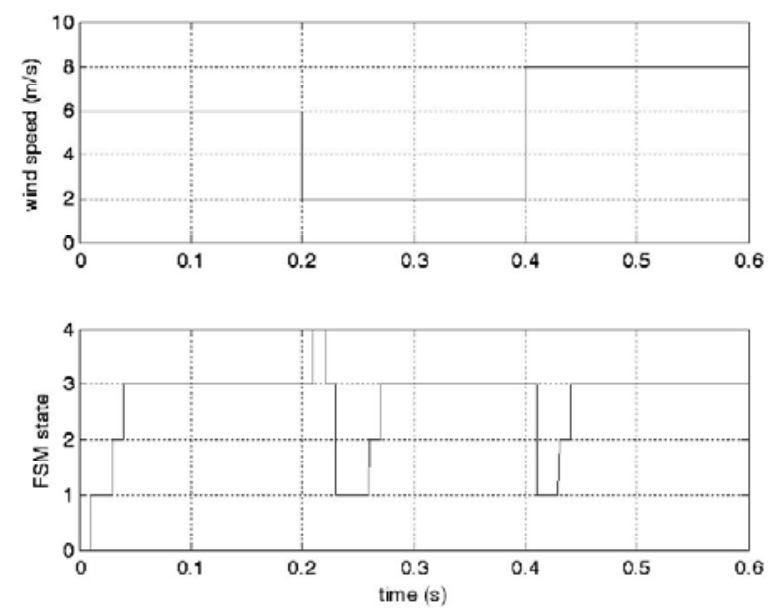

Fig. (5). variation of the current state of the FSM with time, as the wind speed varies.
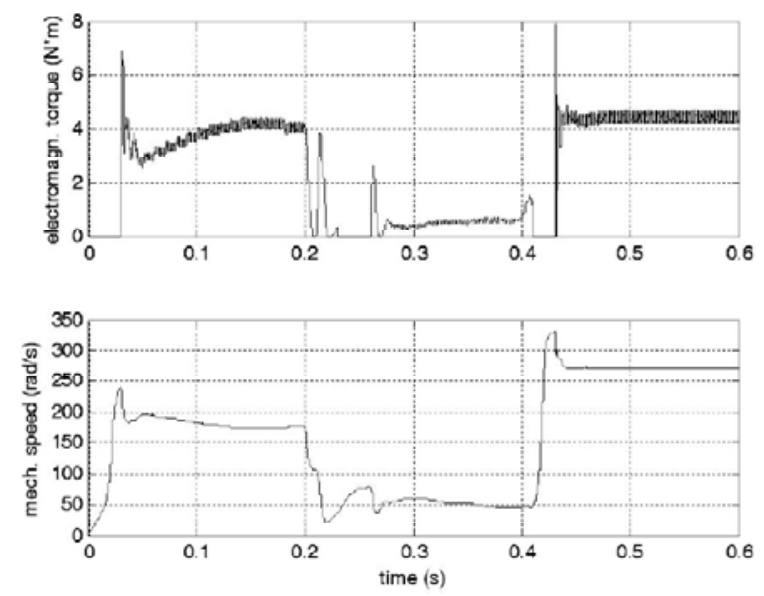

Fig. (6). Electromagnetic torque and mechanical speed of the PMSM machine vs. time.
The first simulation has been carried out at a small time scale, namely 0.6 seconds, to evaluate the steady-state and dynamic performance of the whole control system, including the FSM and the MPPT circuit.

Figs. (5-9) show the behaviour of the system for a challenging situation after start-up: two consecutive step variations of the wind speed towards opposite directions, at $\mathrm{t}=0.2$ $\mathrm{s}$ and $\mathrm{t}=0.4 \mathrm{~s}$ respectively.

Fig. (5) shows the variation of the current state of the FSM with time, as the wind speed varies. Fig. (6) shows the variation with time of the electromagnetic torque and of the mechanical speed of the PMSM machine. As to the main electrical quantities, Fig. (7) shows the input voltage and current of the boost converter, while the DC-link voltage and current are presented in Fig. (8).

It is possible to verify that the system moves through the states as expected and that the MPPT circuit operates correctly. The system exhibits a fast reaction to sudden changes in the wind speed, being the settling time lower than $200 \mathrm{~ms}$ in the worst condition.

Finally, Fig. (9) shows the instantaneous power measured at different sections of the system:

- the mechanical power transferred by the wind turbine to the PMSM;
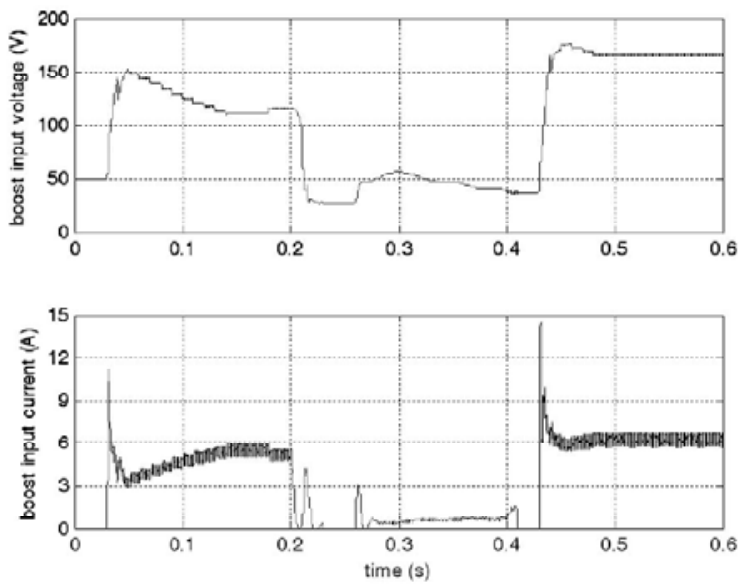

Fig. (7). Input voltage and current of the boost converter vs. time.
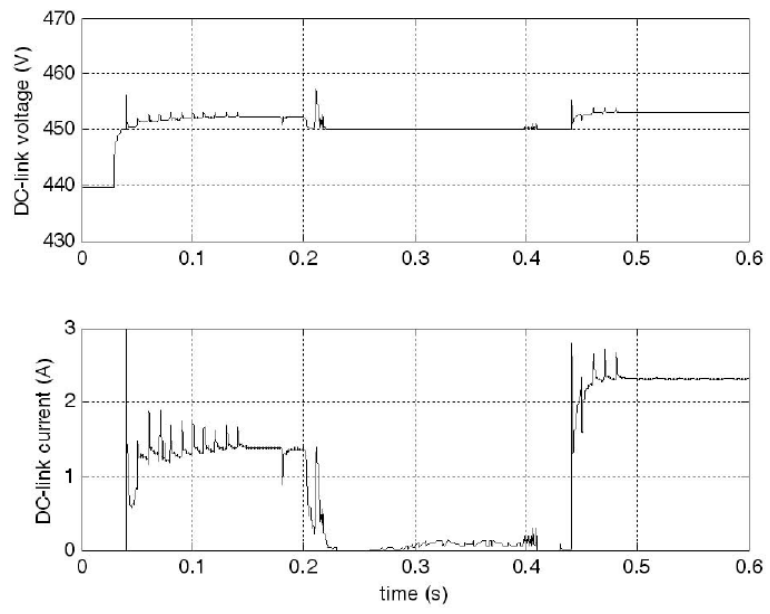

Fig. (8). DC-link voltage and current vs. time. 

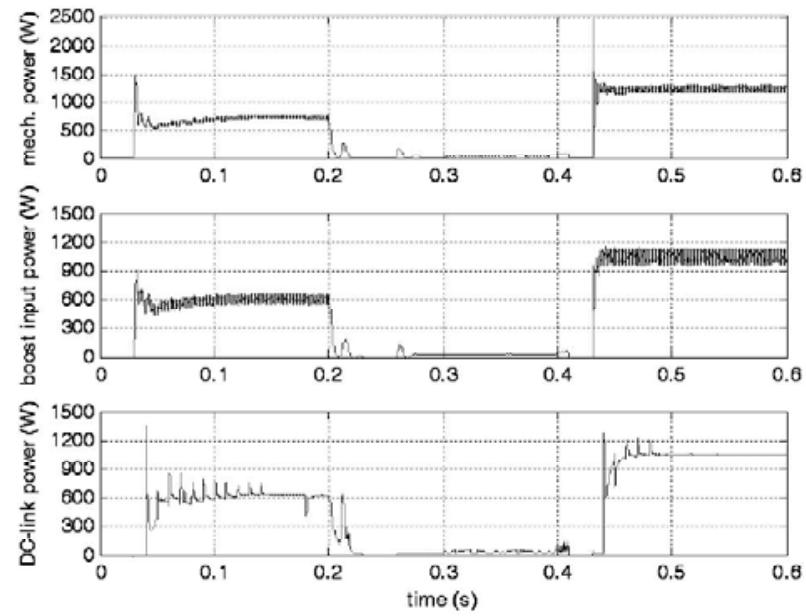

Fig. (9). Instantaneous power measured at different sections of the system.
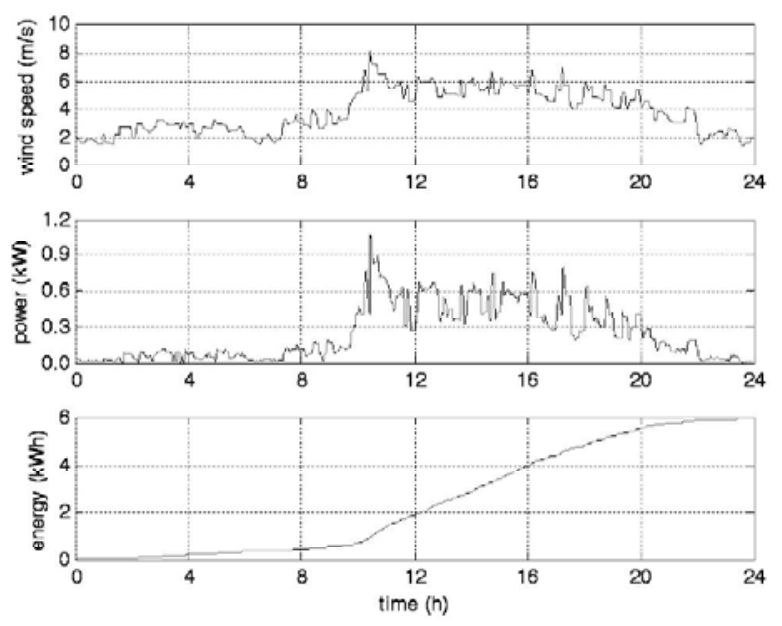

Fig. (10). 24 hours trend of wind speed, power and energy injected into the grid.

- the electrical input power of the boost converter, which is generated by the PMSM and rectified by the diode bridge;

- the electrical power flowing across the DC-link.

The second simulation has been performed at a 24 hours time scale to evaluate the energy production and the capacity factor. Fig. (10) shows the 24 hours trend of wind speed, power and energy injected into the grid in a typical day, which is characterized by almost the same values of the wind parameters given in section II.B: $\min 1.43 \mathrm{~m} / \mathrm{s}$, average $3.84 \mathrm{~m} / \mathrm{s}, \max 8.05 \mathrm{~m} / \mathrm{s}$. As it can be seen, the system generates power even at low speed, thus it is able to deliver about $1 \mathrm{kWh}$ of energy in the quiet hours (from $8 \mathrm{pm}$ to $8 \mathrm{am}$ ). The cut-in speed is about $1.5 \mathrm{~m} / \mathrm{s}$ and the total energy injected into the grid is $5.94 \mathrm{kWh}$.

As a side consideration, by taking into account the speed distribution and the three reference values of Table I and by evaluating the corresponding power levels with the help of another simulation, it has been possible to calculate a value of $5.72 \mathrm{kWh}$ for the energy delivered by the proposed system in a standard day, as shown in Table $\mathbf{V}$.

The comparison with the result of the previous simulation $(5.94 \mathrm{kWh})$ shows a $-3.75 \%$ error, so it is possible to obtain an acceptable estimate of the annual energy production by using this method. Thus, an expected annual production of $2090 \mathrm{kWh}$ is obtained by multiplying the daily energy by 365.25 days.

For a correct performance comparison, it should be considered that the power curves and the annual energy output of commercial micro-wind turbines are often overestimated, as field tests have clearly shown [16-19].

Table VI shows average values for the energy delivered by a conventional micro-wind turbine with a rated power of $1 \mathrm{~kW}$, a peak power of $1.5 \mathrm{~kW}$ and a typical cut-in speed of

Table VI. Energy Delivered by a Conventional $1.5 \mathrm{~kW}_{\mathrm{p}}$ Wind Turbine

\begin{tabular}{|c|c|c|c|}
\hline \multirow{2}{*}{$\begin{array}{c}\text { Average } \\
\text { wind speed } \\
{[\mathbf{m} / \mathbf{s}]}\end{array}$} & \multicolumn{3}{|c|}{ Average Energy Production [kWh] } \\
\cline { 2 - 4 } & Daily & Monthly & Yearly \\
\hline \hline 3.5 & 1.9 & 55 & 680 \\
\hline 4.0 & 2.8 & 85 & 1010 \\
\hline 4.5 & 3.9 & 115 & 1410 \\
\hline 5.0 & 5.1 & 155 & 1850 \\
\hline 5.5 & 6.4 & 195 & 2320 \\
\hline 6.0 & 7.7 & 235 & 2790 \\
\hline 6.5 & 8.9 & 270 & 3260 \\
\hline
\end{tabular}

Table V. Energy Delivered in a Typical Day by the Proposed System

\begin{tabular}{|c|c|c|c|c|}
\hline & Night hours & $\begin{array}{l}\text { Day hours with low } \\
\text { wind speed }\end{array}$ & $\begin{array}{c}\text { Day hours with medium wind } \\
\text { speed }\end{array}$ & $\begin{array}{c}\text { Day hours with high wind } \\
\text { speed }\end{array}$ \\
\hline Speed range $[\mathrm{m} / \mathrm{s}]$ & & $0 \div 4$ & $4 \div 6.5$ & $>6.5$ \\
\hline Reference value for each speed range $[\mathrm{m} / \mathrm{s}]$ & & 2.5 & 5 & 9 \\
\hline Frequency & & $60 \%$ & $34 \%$ & $6 \%$ \\
\hline Time $[\mathrm{h}]$ & & 14.40 & 8.16 & 1.44 \\
\hline Power [W] & & 53 & 385 & 1262 \\
\hline $\begin{array}{l}\text { Energy }[\mathrm{Wh}]= \\
=\text { Power.Time }\end{array}$ & & 763.2 & 3141.6 & 1817.3 \\
\hline Total energy delivered [Wh] & \multicolumn{4}{|c|}{5722.1} \\
\hline
\end{tabular}


$3 \div 3.5 \mathrm{~m} / \mathrm{s}$. The interpolation for an average wind speed of $3.84 \mathrm{~m} / \mathrm{s}$ gives a daily energy output of $2.51 \mathrm{kWh}$ and a value of $904.4 \mathrm{kWh}$ for the annual energy production.

The comparison shows that the energy output of the proposed system (rated power: $0.9 \mathrm{~kW}$; peak power: $1.5 \mathrm{~kW}$ ) is about 2.3 times greater than that of an average micro-wind turbine of the same peak power level, operating at the same average wind speed.

The capacity factor, calculated considering $\mathrm{P}_{\mathrm{C}}$ equal to the rated power in (8), is $26.5 \%$.

\section{CONCLUSION}

The paper proposes a simple, effective and low cost micro-wind energy conversion system, conceived for low speed operation and low power applications connected to the distribution network. The hardware encompasses a micro-wind turbine, a PMSM machine, a diode bridge, a boost DC/DC converter and a grid-connected single-phase inverter. The control is performed by the combination of a finite state machine, a MPPT circuit and a VOC controller, which allow a reliable operation near the maximum power point and a fast response as the wind speed changes, with low losses and null reactive power exchanged with the grid. Different series of numerical simulations have shown that the system architecture and control offer good performance and that the generator can produce more than twice the average energy delivered by a conventional turbine of the same peak power level, operating at the same average wind speed.

\section{REFERENCES}

[1] Ramirez, D.; Veganzones, C.; Blazquez, F. Adaptation of floating point dsp-based technology for small variable-speed wind turbine. IEEE Trans. Energy Conv., 2007, 2(22), 376-382.

[2] Li, D.; Wang, S.; Yuan, P. A Review of Micro Wind Turbines in the Built Environment, Proceedings of the Asia-Pacific Power and Energy Engineering Conference (APPEEC), Chengdu, China, March 28-31, 2010, pp. 1-4.

[3] Lenton, D. Generation Begins at Home, IEE Review, Vol. 51, Issue: 7, 2005 , pp. 24-25.

[4] Infield, D.; Li, F. Integrating Micro-Generation into Distribution Systems - A Review of Recent Research, Proceedings of Power and Energy Society General Meeting - Conversion and Delivery of Electrical Energy in the $21^{\text {st }}$ Century, 2008, pp. 1-4.
[5] Hatziargyriou, N.; Zervos, A. Wind Power Development in Europe, Proceedings of the IEEE, 89(12), 2001, pp. 1765-1782.

[6] Li, H.; Chen, Z. Overview of different wind generator systems and their comparisons. IET Renew. Power Gen., 2008, 2(2), 123-138.

[7] Chan, T.; Loi, Lei, Lai. Permanent-Magnet Machines for Distributed Power Generation: A Review, Proceedings of Power Engineering Society General Meeting, 2007, pp. 1-6.

[8] Burton, T.; Sharpe, D.; Jenkins, N.; Bossanyi, E. Wind Energy Handbook. John Wiley \& Sons, 2001.

[9] Abo-Khalil, A. G.; Lee, D. C.; Seok, J. K. Variable Speed Wind Power Generation System Based on Fuzzy Logic Control for Maximum Output Power Tracking, Proceedings of $35^{\text {th }}$ Annual IEEE Power Electronics Specialists Conference (PESC 04), 2004, Aachen, Germany, pp. 2039-2043

[10] Leidhold, R.; Garcia, G.; Valla, M.I. Maximum Efficiency Control for Variable Speed Wind Driven Generators with Speed and Power Limits, Proceedings of the $28^{\text {th }}$ Annual International Conference of the IEEE Industrial Electronics Society, Sevilla, Spain, November 5-8, 2002, pp. 57-162.

[11] Mohan, N.; Underland, T.; Robbins, W. Power Electronics. New York: Wiley, 1995.

[12] Erickson, R. W.; Maksimovic, D. Fundamentals of Power Electronics, $2^{\text {nd }}$ ed. Kluwer Academic Publishers, 2003.

[13] Malinowski, M. Sensorless Control Strategies for Three-Phase PWM Rectifiers, Ph.D. Thesis, University of Warsaw, Poland 2001.

[14] Malinowski, M.; Kazmierkowski, M. P.; Hansen, S.; Blaabjerg, F. Virtual-Flux-Based Direct Power Control of Three-Phase pwm Rectifiers. IEEE Transactions on Industry Applications, 37(4), July-August 2001, pp. 1019-1027.

[15] Malinowski, M.; Kazmierkowski, M. P.; Trzynadlowski, M. A Comparative Study of Control Techniques for pwm Rectifiers in ac Adjustable Speed Drives, IEEE Transactions on Power Electronics, 18(6), November 2003, pp. 1390-1396.

[16] Brown, H.; Hailes, D. Conclusions and Empirical Data from the First Large Scale Public Field Trial of Building-Mounted MicroWind Turbines, Proceedings of EWEC 2009, Marseilles, France, March 16-19 2009. http://www.ewec2009.info/ and http://www.warwickwindtrials.org.uk/

[17] Turan, S.; Peacock, A. D.; Newborough, M. Micro and small wind turbine applications in the Built Environment, ISESCO Science and Technology Vision, 3(3), May 2007, pp.106-110.

[18] Gipe, P. Testing the power curves of small wind turbines, Summer 2000. http://www.wind-works.org.

[19] Kühn, P. Small Wind Turbine Yield Estimator, Proceedings of 3.BWE-Kleinwindanlagen-Symposium, Husum, Germany, March 20, 2010. Software downloadable from: http://www.windmonitor.de 